\title{
Applications of Edith Stein's empathy theory to Library Science
}

\author{
Katelyn Angell
}

\begin{abstract}
Library Science has traditionally been a discipline which operates from a pragmatic rather than a philosophical framework. Theory is traditionally superseded by practice, rendering librarianship a field lacking in concrete foundations. However, philosophy, particularly phenomenology, harbors powerful ramifications for improving both the theoretical underpinnings and practical applications of the field. In particular, phenomenologist Edith Stein's research on empathy has the unique potential to advance librarianship by providing a model for better understanding of patron needs. In order to translate Stein's theory into practice, the classic feminist strategy of consciousness-raising provides a novel methodology.
\end{abstract}

\section{Introduction}

Historically, there has been a dearth of philosophical approaches to Library Science (LS). Priding itself as a profession constructed by paradigms of pragmatism, the discipline has primarily relied on positivist epistemologies, which translates into an overemphasis on practice and a dearth of sound theory. However, it can be posited that phenomenology, a philosophy which focuses on the conscious experience of a subject, can serve as a useful tool to improve comprehension of the fundamental goals and mores of librarianship. Edith Stein's analysis of empathy and its grounding in phenomenology has boundless potential to advance librarianship in terms of reaching a better understanding of patrons' needs. In order to facilitate the incorporation of empathy into LS education and practice, dependable methods must be employed. The classic feminist tactic of consciousness-raising serves as a germane example. While there are occurrences of phenomenology in Information Science literature as well, the majority of this paper will focus on Library Science.

\section{Author}

Katelyn Angell is a reference librarian at Sarah Lawrence College in Bronxville, New York. Her research interests include feminism, services to seniors, and dismantling information barriers.

Email: katelyn.angell@gmail.com

Received 23 November 2010

Accepted 17 July 2011 


\section{Literature Review}

\subsection{Historical Philosophies of Library Science}

To begin with, librarians have frequently eschewed theory construction to instead concentrate on first-hand professional accounts. According to Gorman (2000), LS professionals have traditionally self-identified as doers rather than thinkers.

We are, then, dealing with a profession that has evolved over many centuries without too much regard to philosophy, overarching principles, and values, but with great respect for the practical, the useful, and the utilitarian.

(Gorman, 2000, 17)

As a result, the preponderance of LS literature consists of individual librarians detailing successful programs and services in their own libraries. While these narratives certainly have the potential to directly improve library services, they do not attempt to create any codified theoretical foundations from which to further expand the profession. In other words, these are inherently positivist epistemologies in nature, focusing on the practical and quantifiable. The positivist school has frequently been utilized in LS research, and continues to enjoy high popularity in the field (Hjørland, 2005). Such a lack of philosophical tactics precludes LS from fully identifying and elucidating its underlying principles.

In order to rectify this problematic situation, it is imperative that librarianship broaden its horizons and incorporate schools of thought which champion the immeasurable yet ubiquitous spheres of human experience. According to Budd (2005):

Not only are several philosophical schools of thought informative, but also they can actually improve practice in information agencies. This is not an empty dictum; they can help us seek truth, and truth is part of any reflective practice.

(Budd, 2005 44)

Thus, just as library practitioners seek to acquire and disseminate materials boasting accurate information, LS theorists desire to utilize methods which will assist the profession in optimally reflecting the authentic facets of its existence. In order for the latter to occur, librarians must serve as active agents to the process.

To begin with larger amounts of theoretical works must be produced and put under strict peer review. A theoretical shift in librarianship is only possible if a vibrant literature is there to support it. The second and more challenging shift would have to come on the working librarians end. It is the responsibility of librarians to engage with theoretical works and adopt a new reflective posture towards their own work.

(Burton, 2009, 26)

In other words, a thorough and ongoing examination of LS's ontologies and epistemologies, propelled by steadfast collaboration between academics and practitioners, must precede the implementation of novel library services. 


\subsection{Phenomenology}

Although there are a multitude of philosophies with practical applications for LS, phenomenology in particular offers the field substantial opportunities for growth (Budd, 2005). Founded in the early $20^{\text {th }}$ century by German professor Edmund Husserl, phenomenology is defined as:

A method or procedure... which involves the setting aside of presuppositions about a phenomenon as an empirical object and about the mental acts concerned with experiencing it, in order to achieve an intuition of its pure essence.

(Oxford English Dictionary, 2008)

Dissatisfied with the dominance of a scientifically driven positivism during this era, Husserl was distrustful of empiricism, as he believed that sensory experience alone could not fully account for the entirety of truth or knowledge. Instead, he sought to bring some respect for human reasoning back to philosophy, confident that the analysis of consciousness and their phenomena would create a true fountainhead for human knowledge.

According to Husserl, phenomenology requests that individuals disregard their preconceived notions about a particular thing, as failure to do so precludes the person in question from fully grasping the thing's essence (the what it is). "Phenomenology is a science that calls for a return to things themselves rather than fixing on interpretations of those things" (Balaban, 2002, 104). Husserl called the latter the natural standpoint, and encouraged his followers to take the former standpoint, one which brackets the idea of objects as real and instead examines how intentionality allows us to constitute them. To more clearly elucidate this idea, Sawicki (1998) offers an insightful illustration:

I constitute an object in consciousness: for example, this lectern. This doesn't mean I have a little lectern in my head, or even a little picture of a lectern. No, I have a sense or notion of the lectern. This is the object 'intended' by my consciousness.

(Sawicki, 1998)

This alternative offers us a method of perceiving the fundamental nature of a particular object formerly unattainable, one which does not limit an object's identity to its simple external appearance. Indubitably, the idea of consciousness is integral to Husserl's interpretation of phenomenology. Signifying mental awareness, consciousness allows a person to competently differentiate between the self and external things or events. Additionally, consciousness is endowed with intentionality, a term originally coined by his professor, Franz Brentano. Commonly referred to as "aboutness," intentionality proposes that every mental act, such as judgment or love, is directed at a particular object or event.

\subsection{Phenomenography}

At this point it is important to ensure that phenomenology is properly distinguished from phenomenography, a qualitative approach to educational research which is beginning to be utilized by information scientists (Rose, Le Heron and Sofat, 2005; Andretta, 2007; Cope and Staehr, 2008). While both 
phenomenology and phenomenography are centered on exploring and analyzing human experience, they differ greatly, as the former is rooted in philosophy and self-exploration, while the latter is constructed upon empiricism and focuses on the experiences of those outside of the self.

Explaining this major distinction, Andretta (2007) writes that in phenomenology:

It is the researcher's perspective that is examined through reflection on his/her experience of the world. This is achieved by dissociating oneself from the natural attitude where the process of experiencing is taken for granted. From the outset such a philosophical approach aims to develop a single theory of experience. Phenomenography, on the other hand, employs an empirical approach to study other people's perspective of the world and devise collective categories that describe the variation of this experience (Marton and Booth, 1997, p. 116).

(Andretta, 2007, 153-154)

In other words, phenomenology focuses upon a phenomenon itself (its essence), whereas phenomenography explores the relationship between a phenomenon and the individuals involved with it. While additional elaboration upon phenomenography is beyond the scope of this paper, applications of phenomenography in Information Science can be found in Andretta's work on information literacy (2007) and Cope and Staehr's (2008) work on information systems as social systems.

\section{Applications to Library Science}

In recent years, several LS researchers have attempted to delineate the potential of phenomenology to influence LS practices. To begin with, it has been posited that phenomenology can be substituted for the positivistic research methodologies Budd (1995) identifies as frequently borrowed by LS from the social sciences. While quantitative methods associated with positivism previously predominated LS research, less emphasis is presently placed on these traditional techniques, with researchers instead choosing to focus on the holistic experience of the individual information seeker.

The growth in the popularity of qualitative research methods in this field [LS] stems from a realisation that the mere counting of occurrences of actions (such as borrowing books or buying journals) is inadequate for an understanding of the aims and motivations of the information seeker.

(Wilson, 2003, 448)

Thus, phenomenology encourages the discipline to venture beyond mechanistic and numerical techniques - to focus instead on the experiential, which is highly relevant to a profession defining itself as user-centered (Jennings, 2009).

As an alternate epistemology, phenomenology offers LS researchers ample room for knowledge construction which takes into account varying humanistic as well as physical phenomena.

Thinking within LS should be more skeptical of methods and practices that purport to offer suggestions of causality based on the examination of limited variables or aspects of a phenomenon. The revised thinking should be, as Harris 
says, more holistic; that is, we should explore not only behavioral outcomes but also contextual influences on human action, such as political, social, cognitive, and cultural aspects of the situations of, for instance, library users.

(Budd, 1995, 315)

Such a metaphysical approach, in contrast to positivism, would provide a theoretical foundation for the development of clear professional goals, which could then be translated into action by librarians endowed with a greater understanding of their job's vision.

In addition, phenomenology has been utilized to investigate information seeking behaviors. Ng (2002) used Alfred Schutz's phenomenology of sociology to examine the significance of both situation and planned action to information retrieval (IR) in human-computer interaction (HCI). Working off of Schutz's concept of sedimentation, which details how new knowledge is combined with an individual's pre-existing knowledge, $\mathrm{Ng}$ found that information seekers familiar with a particular context (situation) more closely adhered to a pre-configured plan than less experienced seekers.

Focusing only on either the situated-ness or the planned-ness of information seeking action and interaction to characterize IR [information retrieval] or $\mathrm{HCI}$ may result in an unrealistic model. There may be tension between situated-ness and planned-ness, but only when we take both of them into account can we develop successful models for IR interaction and for better interface design.

(Ng, 2002, 624).

Thus, both of these user-related factors, situation and planning, can be combined to create a unified, comprehensive IR model, allowing seekers to grasp the true essence of the information in question.

Notably, intentionality, an integral aspect of phenomenology, holds fascinating potential for LS. During Husserl's prolific career, he began to explore the German concept Einfühlung, which upon translation to the English language adequately describes our comprehension of the word empathy. Empathy is the first-person experience of intersubjectivity, which allows for two subjects to share a mutual situation. According to Thompson (2001):

Empathy is a unique and irreducible kind of intentional experience: although it is based on sense perception and may involve inference (in difficult or problematic situations), it is not reducible to some additive combination of two, after the fashion of the theory that we understand others by perceiving their bodily behavior and then inferring or hypothesizing that their behavior is caused by particular experiences or inner mental states. Rather, we experience another person as a unified whole through empathy.

(Thompson, 2001, 16)

Thus, empathy enables an individual to broaden his/her realm of knowing, as we are able to experience another as a subject instead of as simply an object. Such a process is truly transformative, as it snatches us from our own limited perceptions and opens up to us a world of mutual experiences. 
Although Husserl touched upon the concept of empathy during his career, his student and research partner Edith Stein explored the idea in much greater detail. In particular, she tackled the esoteric concept in her dissertation, On the Problem of Empathy, published at the precocious age of twenty-five. While much of her work was influenced by Husserl's research, Stein unquestionably contributed a purely original set of findings to the literature, many of which have influenced modern philosophers, medical practitioners, and community activists. According to Stein, the primary goal of phenomenology is to discover the foundation of all knowledge, and empathy is the means by which we "arrive at knowledge of the human essence" (Wright, 2003, 113). Thus, this materializes as a specific epistemology, focusing on the uncovering and amalgamating of knowledge concerning the quintessence of human nature.

Before continuing to analyze Stein's work, it is imperative to proffer her connotation of empathy. An act of perceiving, empathy involves two distinct subjects. She explains:

And while I am living in the other's joy, I do not feel primordial joy. It does not issue live from my "I." Neither does it have the character of once having lived like remembered joy... This other subject is primordial although I do not experience its primordiality; his joy is primordial although I do not experience it as primordial. In my non-primordial experience I feel, as it were, led by a primordial one not experienced by me but still there, manifesting itself in my nonprimordial experience.

(Stein, 1964, 11)

Thus, Stein's theory of empathy maintains that people are not solitary in their feelings and experiences; empathy allows two individuals to understand each other and share prevailing human occurrences, such as joy or sadness. This is enabled because of the identification of and interaction with a foreign consciousness. However, as explained above, empathy does not signify complete unification, as that would erase one's individual "I." For example, although X can experience initial sadness upon learning of a tragedy affecting $Y, X$ 's actual suffering is reserved for her, obtained by Y only nonprimordially. Stein's empathy hermeneutic harbors bountiful possibilities for profound social change, precisely because it entails that people recognize their peers as similar to themselves.

According to Sawicki (1998), Stein's major accomplishment:

Is the description of the "I" in its fundamental orientations toward other "I"s: as alternately a trailblazer of courses of experiences that others may follow, and a follower who re-enlivens and amplifies the courses opened up by others.

(Sawicki, 1998)

Thus, Stein's empathy process results both in a more concrete knowledge of one's own self and others. Such a relational method is the perfect antidote for a society conditioned to fear or ignore difference, as it reiterates the certainty of human equality.

Presently, there is a dearth of literature on implications of empathy for librarianship. Conventionally, the notion of empathy has mainly been associated 
with the medical profession. However, certain parallels can be drawn between medicine and librarianship, specifically that both professions focus on fostering and nurturing human development. In one instance, Stein's concept of empathy is explored in the context of its relevance to the nursing profession (Määtä, 2006). Although Stein did not believe that empathy could be taught, indirect methods could be utilized to help nurses understand their patients better. For example, "activities that increase self-awareness, active listening, respect, and tolerance for differences can facilitate the occurrence of empathy" (7).

Additionally, there is evidence of demonstrated need for more empathy training in medical school for future doctors, as well as the creation of instruments and tools to measure empathy. This is especially apparent upon learning that research has shown empathy levels to deteriorate among students as medical school progresses (Singh, 2005). There are remedies for this problem, however.

'Narrative medicine,' which uses instruments, such as reflective writing, is being taught in more and more medical schools. Students can improve their capacity for empathy, reflection, and professionalism through serious narrative training.

(Singh, 2005, 3)

Thus, these two people-oriented professions have demonstrated steps toward raising awareness of the major significance of empathy; now it's librarianship's turn.

A review of LS online databases reveals a limited body of research on the role empathy plays in librarianship. Because a librarian's cardinal function is to provide information to a diverse audience, it is of the utmost importance that he/she understands the information needs and wants of this information group. Thus, empathy, which allows an individual to identify with and comprehend the experiences and feelings of another, is virtually an essential requirement of the profession. According to Johnson (2009), empathy is an integral tool for success in today's global environment, as discernment of others' needs results in enhanced service provision. A choice method of building empathy is reading fiction. Explaining his reasoning, Johnson writes:

Viewing the world through the eyes of a narrator completely unlike oneself, draws into sharp detail the differences of experience, but also the similarities - common human traits - that we come to know others as people, not just stereotypes.

(Johnson, 2009, 98)

This approach is valid for adults as well as children, and should be championed by libraries serving all user groups.

Cranford (2000) offers additional insightful and practical advice on empathybuilding for public librarians. Likening first-time library patrons to visitors to a foreign country, unfamiliar both with local customs and dialects, she urges librarians to identify with their potentially anxious patrons. Reacting to inquiries impatiently or brusquely could result in the undesirable possibility that patrons will use this one incident to blacklist the library in the future. In order to best serve patrons, the goals of librarians should be: 
To provide our patrons with finding tools which help them successfully navigate our collections and our buildings, interact with them in ways that ease their initial anxieties, and help them overcome any initial disadvantages so that they think well of their experiences with us and want to return again and again.

(Cranford, 2000, 34)

In a recent literature review, Miller and Wallis (2011) discuss the significance of empathy as a nonnegotiable interpersonal skill in social interaction between information professionals and clients. The authors generate eight specific jobrelated duties in which empathy would be an integral component of professional success. These duties include "information counselling or coaching for positive change," "stimulating creativity, innovation and generating solutions to problems," and "building collaborative working relationships with clients and colleagues" (Miller and Wallis, 2011, 129). Translated to librarianship, examples of these three principles, in sequential order, could be one-on-one reference consultations, active group bibliographic instruction sessions in a participatory learning environment, and consciousness-raising groups, which will be explained later.

While the aforementioned articles on empathy all contain plausible suggestions for empathy-building in librarianship, none are framed in the context of a qualitative study. In order to better investigate a library community's actual perceptions of and relationships to empathy, Birdi, Wilson and Tso (2009) conducted two studies in order to ascertain how public library staff members' cultural identities impact their interactions with their patrons. Data gathered from the studies' library staff participants suggests that in general librarians view each other as empathetic individuals.

However, there is evidence which suggests that in order to truly display empathy, which is defined here as "an emotional response based on instinct and shared understanding" (Birdi, Wilson and Tso?, 2009, 88), librarians should learn more about cultures external to their own. One method of accomplishing this goal could be to create cultural awareness training programs for library staff. Such programs could give librarians a foundation for understanding values and customs of cultures outside of their own, helping increase their sensitivity to people from different cultural backgrounds. Extolling the benefits of empathy in librarians, one study participant says:

Very often, users might not tell you what they want in a very direct way. The ability to empathize allows me to become more sensitive, like a detective, so as to explore what users need better. This ability is beneficial to the librarian as a professional.

(Birdi, Wilson and Tso, 2009, 86)

In order for librarians to optimally serve their community, they must be fully aware, or conscious, in phenomenological terms, of their patrons' wants and needs. This is particularly valid in terms of populations which have historically been underserved or underrepresented in many public services. Librarians cannot assume that by virtue of their professional status they automatically can sufficiently meet the needs of every member of their diverse clientele. Such a 
hasty supposition can result in false consciousness, which indisputably hinders the flattening of the information access hierarchy.

As the gatekeepers of information in a capricious society, librarians are endowed with an impressive amount of power. In order to exercise this power in a just manner, it is imperative for them to properly understand and identify with their patrons, and work with them to generate collectively beneficial information acquisition and retrieval plans. In order for this to be accomplished, an empirical approach, which gathers knowledge via observation of the natural world, is unsatisfactory. A phenomenological approach, which proposes alternate methods of knowing the world, is better suited to this context. In particular, empathy has the potential to enhance library service. With respect to its applications, empathy can be promoted in the library environment by way of a classic feminist tactic called consciousness-raising.

During the late 1960s, a small group of New York feminists applied a prominent Civil Rights political activist strategy, consciousness-raising (C-R), to the feminist movement. Utilized primarily as a tool to raise awareness, C-R allowed individual women to explore oppression experienced in their own lives, and bond with others over shared experiences. Women began to form C-R groups, where they realized the ubiquity of female oppression and the importance of solidarity in toppling this subjugation. According to Sarachild:

In the end the group decided to raise its consciousness by studying women's lives by topics like childhood, jobs, motherhood, etc. We'd do any outside reading we wanted to and thought was important. But our starting point for discussion... would be the actual experience we had in these areas. One of the questions, suggested by Ann Forer, we would bring at all times to our studies would be -who and what has an interest in maintaining the oppression in our lives.

(Sarachild, 1978, 145)

Once women compiled the first-hand research needed to give them a solid understanding of their oppression, they could competently proceed to develop a concrete agenda, or plan of action.

In terms of structure, $\mathrm{C}-\mathrm{R}$ groups were kept as non-hierarchical as possible. Typically, groups met weekly at a member's house, and rarely exceeded twelve women. Discussion of C-R topics, which were frequently relegated by sceptics as "personal" female problems, revealed the truth of the matter: they were indeed very political in nature. Ellen Willis elaborates on external criticism of C-R groups and provides an eloquent line of defence. She writes:

This $(C R)$ process, so often misunderstood and disparaged as a form of therapy, uncovered an enormous amount of information about women's lives and insights into women's oppression, and was the movement's most successful organizing tool.

(Willis, 1984, 21)

CR-groups provided an ideal forum for women to better understand themselves and their position in relation to others. In other words, CR-groups produced a united and powerful feminist consciousness stimulated by empathy. 
Although C-R has rarely been considered a tactic useful for librarianship, analysis of the tactic helps bring to light its latent possibilities. In a paper analyzing the applicability of aspects of feminist scholarship to LS research, Spivey (1995) cites consciousness-raising as a compelling technique for information gathering.

Role playing, simulations, diary-keeping, autobiography, and group discussions (as opposed to individual interviews) for obtaining diverse data are some of the techniques used in consciousness-raising.

(Spivey, 1995, 163)

In this instance, however, group discussions are going to be the sole focus. The creation of C-R groups has projected benefits for librarians, patrons, and LS students, and can be formulated in both library and scholastic settings.

In the first case, C-R groups will be composed of both library staff and patrons, and will function as a forum in which patrons can discuss positive and negative library experiences, as well as recommend specific materials and services. Thus, librarians will have an opportunity to formally meet and better understand their patrons. As Stein pointed out, however, empathy is not a one-way process patrons will also empathize with librarians, gaining a better grasp of potential limitations facing librarians, such as budget crises and censorship issues. In this context, both the librarian and the patron are subjects, placed on equal footing with one another; the patron is no longer the object at which the librarian unrestrictedly directs his/her actions or intentionality. The groups award patron and librarian alike the ability to relate to foreign consciousnesses, which enables both parties to look outside of themselves and view the world from a universalistic perspective.

Since the majority of empathy research in librarianship has thus far focused on public libraries (Miller and Wallis, 2011), it is beneficial to explore the possibilities of consciousness raising groups in an academic library setting. In order to ensure that collections are strong in areas concentrating on historically marginalized populations (e.g. Disability Studies, Queer Studies, Native American Studies, and Fat Studies), collection development librarians can invite faculty and students (either individually or as a student group) to meet with them. At this group meeting, faculty/students can dialogue with the librarians about the particular area of study, exploring gaps in the collection and devising strategies to rectify these holes. If librarians are unfamiliar with these topics, which generally combine a robust history of activist strategies with academic theory, this could be a perfect opportunity for them to learn from participants and students of the movement/area of study. Students/faculty, in turn, can become better acquainted with the library's acquisition and organization processes - both of which could assist them in their library research.

By initiating such a meeting, librarians would demonstrate their commitment to and interest in fine-tuning the collection to the wants and needs of its users - in this particular instance to a group of users whose bodies of knowledge have traditionally been underrepresented on library shelves. If the patrons in attendance wished they could also use this time to inquire with the librarian about decisions 
behind the collection's size, quality, condition, and temporal relevancy basically, the criteria the librarian utilizes to create and maintain the collection. Patrons would be encouraged to offer suggestions they believe would benefit the library, as well as critique aspects of the collection contrary to the goals or content of the discipline (e.g. the presence of homophobic material in the Queer/LGBTQ Studies section).

Such frank discussion on the part of the creators/acquirers/organizers (librarians) and the creators/consumers (patrons) would invariably produce positive results specifically, empathy, or a mutual understanding of each other's unique location in the academy. A greater sense of trust will be established between librarian and patron, as investing in the group discussion will yield a more thorough and relevant collection for the users and more assurance to the librarian that the purchasing decisions they make are valued and sincerely based upon the specific needs of the community.

This initial meeting will purportedly begin an equitable dialogue between the library and the patrons, encouraging communication that is based upon mutual understanding and identification of a common goal - a strong library collection created through decisions made jointly and openly.

Additionally, LS educators can help their students prepare for an empathic and productive library career by creating C-R groups. Although faculty and students hold different positions on the university hierarchy, such distinctions will be removed in terms of C-R group structure. Faculty may use their personal and professional experiences to make positive contributions to topical discussions, but the importance of intersubjectivity to the group's healthy functioning should not be forgotten. A different topic relating to the ethics, responsibilities, etc. of librarianship could be broached at each meeting, with the primary focus on the generation and identification of shared empathic tactics.

\section{Conclusion}

In conclusion, both the theory and practice of librarianship stand to benefit from an expansion of philosophical approaches. In particular, Edith Stein's study of empathy as an aspect of phenomenology offers much insight for improved services to heterogeneous user groups. Tactics such as consciousness-raising can expedite this process. By allowing separate people to better understand each other, empathy breaks down socially imposed barriers of problematic individualism and ignorance, encouraging people to unite on the common theme of humanity. 


\section{References}

Andretta, S. (2007) Phenomenography: a conceptual framework for information literacy education. Aslib Proceedings, 59(2), 152-168.

Balaban, O. (2002) Epoche: Meaning, object, and existence in Husserl's phenomenology. In: A. Tymieniecka (ed.) Phenomenology world-wide: foundations - expanding dynamics - life-engagements - a guide for research and study. Boston: Kluwer Academic Publishers. 103-114.

Birdi B., Wilson, K. and Tso, H.M. (2009) The nature and role of empathy in public librarianship. Journal of Librarianship and Information Science, 41(2), 8189.

Brownmiller, S. 2000 In our time: memoir of a revolution. New York: Dial Press.

Budd, J.M. (2005) Phenomenology and information studies. Journal of Documentation, 61(1), 44-59.

Budd, J.M. (1995) An Epistemological Foundation for Library and Information Science. The Library Quarterly, 65(3), 295-318.

Burton, J. (2009) Theory and politics in public librarianship. Progressive Librarian, 32, 21-28.

Chicago Women's Liberation Union (1971) How to start your own consciousnessraising group. URL: http://www.uic.edu/orgs/cwluherstory/CWLUArchive/crcwlu.html [accessed 26.6.11].

Cope, C. and Staehr, L. (2008) Improving student learning about a threshold concept in the IS discipline. Informing Science, 11, 349-364.

Cranford, J.L. (2000) Exercises in empathy. Arkansas Libraries, 57(5), 32-34.

Gorman, M. (2000) Our enduring values: librarianship in the 21st century. Chicago: American Library Association.

Hjorland, B. (2005) Empiricism, rationalism and positivism in library and information science. Journal of Documentation, 61(1), 130-155.

Jennings, S.L. (2009), Creating a user centered environment... What do our patron want? Tennessee Libraries, 59(2). URL:

http://www.tnla.org/displaycommon.cfm?an=1\&subarticlenbr=301 [accessed 08.8.11].

Johnson, D. (2009) Building Capacity for Empathy, Library Media Connection, 27(4), 98.

Määttä, S.M. (2006) Closeness and distance in the nurse-patient relation: the relevance of Edith Stein's concept of empathy. Nursing Philosophy, 7, 3-10.

Miller, F., and Wallis, J. (2011) Social interaction and the role of empathy in information and knowledge management: a literature review. Journal of Education for Library and Information Science, 52(2), 122-132. 
$\mathrm{Ng}$, K.B. (2002) Toward a theoretical framework for understanding the relationship between situated action and planned action models of behavior in information retrieval contexts: contributions from phenomenology. Information Processing and Management, 38(5), 613-626.

The Oxford English Dictionary (2008) Phenomenology. Oxford University: OED Online.

Rose, E., Le Heron, J. and Sofat, I. (2005) Student understandings of information systems design, learning and teaching: a phenomenography approach. Journal of Information Systems Education, 16(2), 183-195.

Sarachild, K. (1978) Consciousness-raising: a radical weapon. In: Redstockings (ed.) Feminist revolution. New York: Random House. 144-150.

Sawicki, M. (1998) Personal connections: the phenomenology of Edith Stein, URL:

http://www.library.nd.edu/colldev/subject home pages/catholic/personal connect ions.shtml [accessed 27.6.11].

Sawicki, M. (1997) Empathy before and after Husserl. Philosophy Today, 41(1/4), 123-127.

Singh, S. (2005) Empathy: lost or found in medical education? MedGenMed, 7(3), 74.

Spivey, M.A. (1995) Feminist scholarship: implications for information management and research. The Journal of Academic Librarianship, 21,159-166.

Stein, E. (1964). On the problem of empathy. The Hague: Martinus Nijhoff.

Thompson, E. (2001) Empathy and consciousness. Journal of Consciousness Studies, 8(5-7), 1-32.

Willis, E. (1992) No more nice girls: countercultural essays. Middletown: Wesleyan University Press.

Wilson, T.D. (2003) Philosophical foundations and research relevance: issues for information research. Journal of Information Science, 29(6), 445-452.

Wright, T. 2003 Phenomenology and the moral imagination. Logos, 6(4), 35-50.

\section{Open access and copyright}

Library and Information Research is an open access journal. A freely available copy of this paper may be downloaded from the journal's website:

http://www.cilipjournals.org.uk/lir

Copyright and associated moral rights in works published in Library and Information Research are retained by the author(s) but this paper may be used freely, with proper attribution, in educational and other non-commercial settings. 